\title{
Aporte de la Ley Orgánica de Ordenamiento Territorial-LOOT, para la gestión turística territorial en Colombia
}

\author{
Contribution of the organic law of territorial planning \\ to the tourism management in Colombia
}

Martha Cecilia Torres López*

Citar este artículo como: Torres, M. C. (2016) "Aporte de la Ley Orgánica de Ordenamiento Territorial -LOOT, para la gestión turística territorial en Colombia”. Revista Nodo, 10(20), pp. 25-37

\section{Resumen}

La Ley Orgánica de Ordenamiento Territorial (Ley $1454,2011)$ define un marco general que considera al Ordenamiento Territorial como el instrumento de planificación y gestión para promover el aumento de la capacidad de descentralización, planeación, gestión y administración de sus propios intereses en las entidades territoriales y en las instancias de integración regional propuestas. El presente documento pretende articular esta Ley con las normativas nacionales y los lineamientos expedidos por las organizaciones dedicadas al estudio y gestión del turismo a nivel mundial y nacional, con el fin de servir como soporte en la configuración de estrategias regionales para la gestión de destinos turísticos sostenibles y competitivos, concluyendo en las competencias que en materia turística indican las normativas y sus instrumentos asociados, con el fin de dar cumplimiento a la Carta Magna en la consolidación de un "Estado social de derecho, organizado en forma de República unitaria, descentralizada, con autonomía de sus entidades territoriales, democrática, participativa y pluralista".

\section{Palabras clave}

Desarrollo regional, Turismo, Régimen jurídico, Colombia

\section{Abstract}

The Organic Law of Territorial Planning (Law 1454, 2011) defines a general framework which considers the Territorial Planning as an instrument planning and management to promote capacity for decentralization, planning, management and administration of their own interests in the entities territorial and regional integration organizations proposals. This document aims to articulate this Law with national regulations and guidelines issued by organizations dedicated to the study and management of tourism at global and national level, in order to serve as a support in shaping regional strategies for managing destinations tourist sustainable and competitive, concluding the powers in tourism indicate the regulations and associated instruments in order to comply with the Constitution in the consolidation of a

Fecha de recepción: 14 de marzo de 2016 Fecha de aceptación: 20 de mayo de 2016

* $\quad$ Arquitecta U.N. Especialista en Gerencia de Diseño U.J.T.L. Mg. en Gestión Urbana U.P.C. Consultora y asesora en Gestión del Turismo y en Gestión Curricular. Universidad La Gran Colombia, Universidad Colegio Mayor de Cundinamarca. diseno. midas@gmail.com 
"social state of law, organized as a unitary republic, decentralized, with autonomous territorial units, democratic, participatory and pluralistic ".

\section{Keywords}

Regional development, Tourism, Legal systems, Colombia

\section{Introducción}

La Constitución Política de 1991 ordena la expedición de la Ley Orgánica de Ordenamiento Territorial -LOOT, con el objetivo de "distribuir competencias entre la Nación y las entidades territoriales" (Artículo 286) ${ }^{1}$-incluyendo en esta categoría a regiones y provincias (Artículo 307, 321)-; también "fijar las condiciones para la creación de nuevos departamentos" (Artículo 297); "definir las condiciones para el funcionamiento de las Áreas Metropolitanas" (Artículo 319); y "establecer la conformación de las entidades territoriales indígenas" (Artículo 329). Transcurridos 20 años de ser ordenada y después de haber sido presentada 19 veces ante el Congreso de la República, la Ley Orgánica expedida (Ley 1454, 2011) define un marco general que considera al Ordenamiento Territorial como el instrumento de planificación y gestión (Artículo 2), que permita promover el aumento de la capacidad de descentralización, planeación, gestión y administración de sus propios intereses, en las entidades territoriales y en las instancias de integración regional propuestas (regiones administrativas y de planificación, regiones de planeación y gestión, asociaciones de entidades territoriales, áreas metropolitanas y provincias administrativas y de planificación).

Aunque se esperó que esta Ley Orgánica, por su jerarquía, asumiera de manera directa las directrices relativas a la asignación de competen-

1 Artículo 286. Son entidades territoriales los departamentos, los distritos, los municipios y los territorios indígenas.

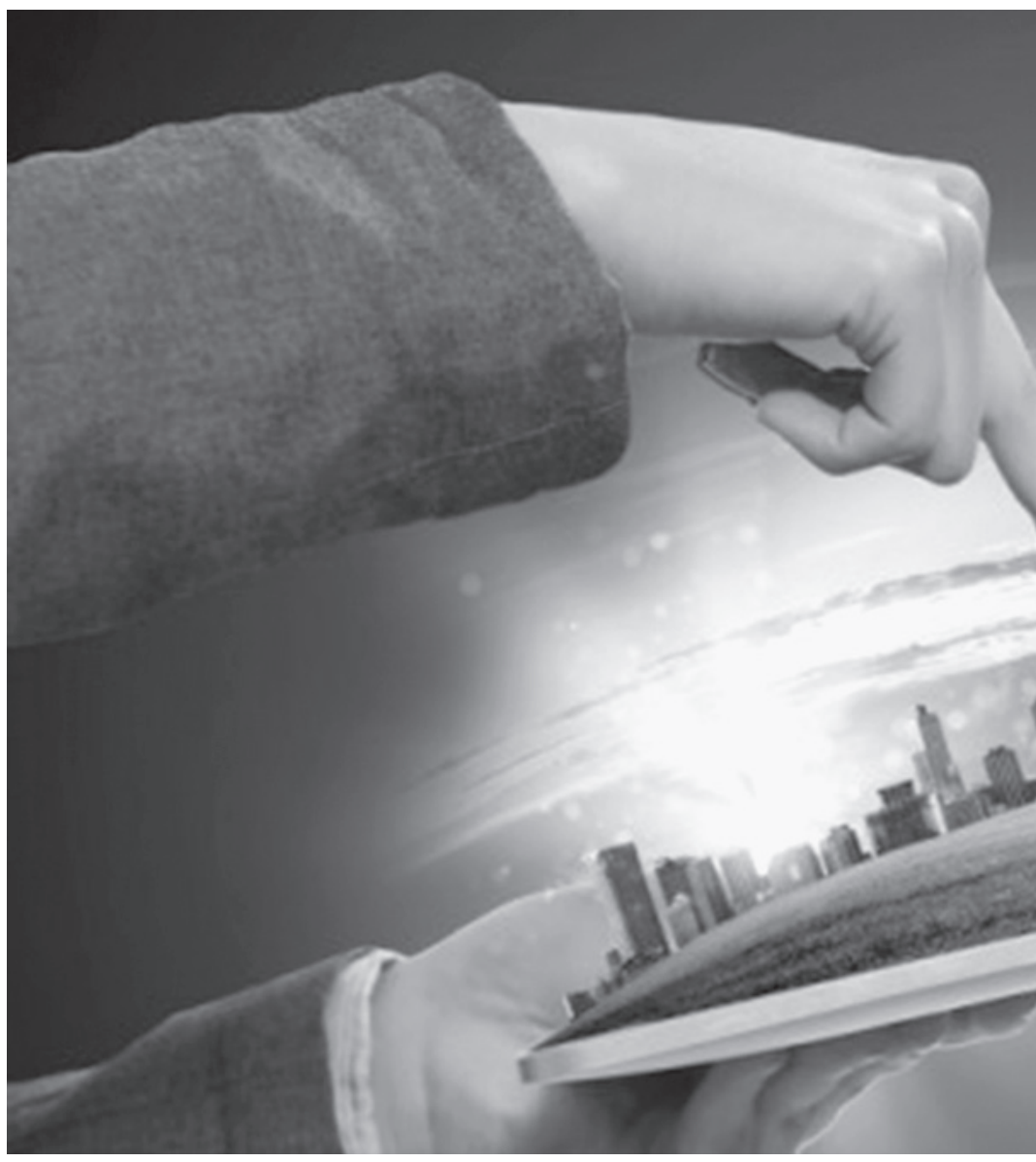

cias normativas para las entidades territoriales (Olano García, 2008), en cada uno de los sectores de la economía nacional y regional, el turismo, en el caso específico de estudio de este documento, entrega opciones globales dirigidas a la configuración de destinos, aunque ello, dada la demora en su promulgación, implica continuar la Visión desde la interrelación de diversas normativas, tanto para lo territorial como para lo sectorial, que puedan permitir una adecuada planificación y gestión en los ámbitos regionales y locales que han venido construyéndose.

En este sentido, el presente documento relaciona de manera sistemática estos lineamientos y normas en el ámbito territorial, con el fin de servir de base para establecer conexiones significativas entre la gestión del turismo como sector productivo y su impacto en el territorio identificado como turístico, definiendo de manera preliminar y como 


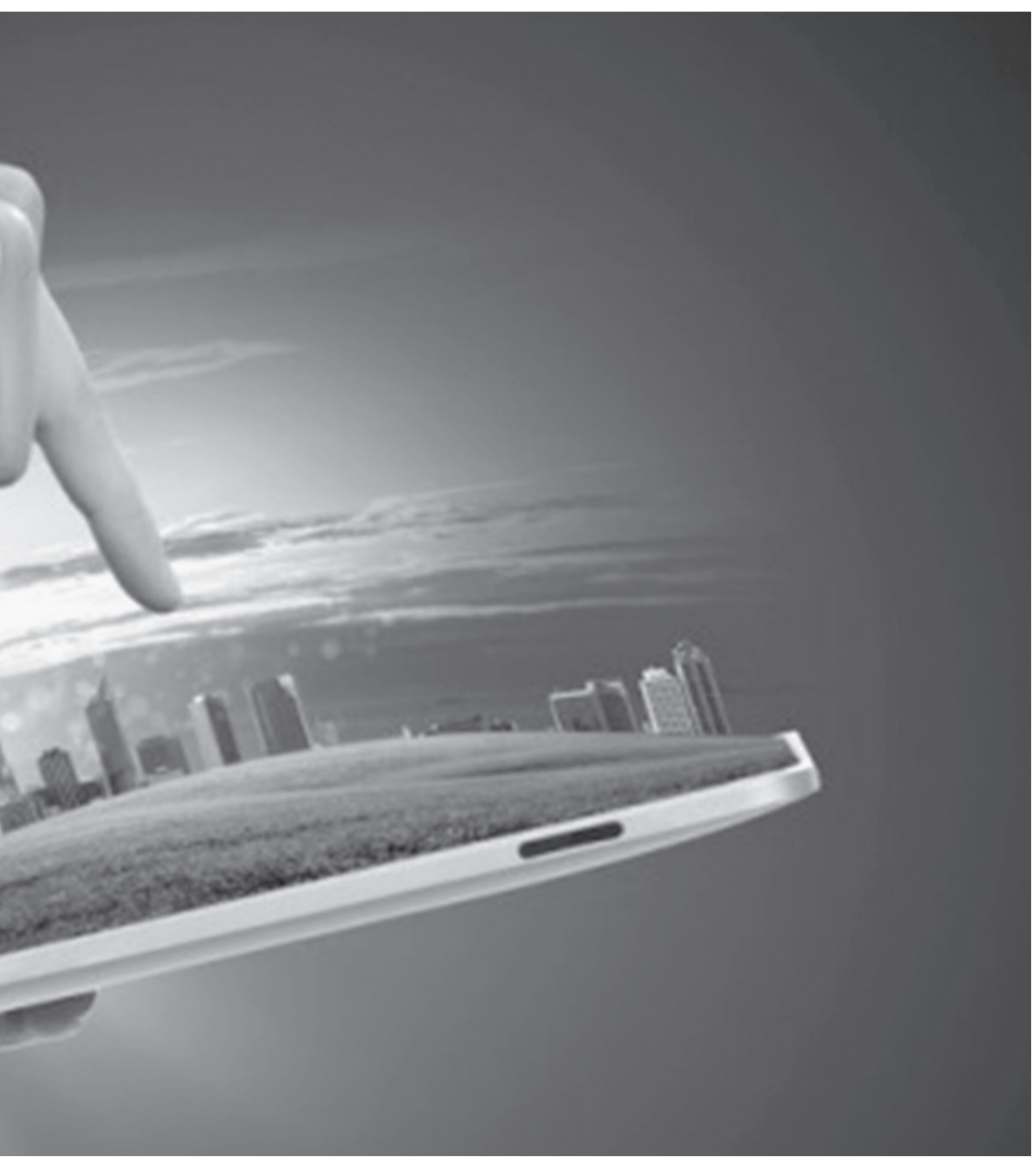

propuesta de gestión, las competencias que debe asumir cada una de las entidades territoriales, en cumplimiento de lo expuesto en la Política de Estado (Política Nacional de Competitividad y Productividad, 2008) en aras de convertir a Colombia en un destino turístico de clase mundial.

\section{Relaciones básicas entre territorio y turismo}

El turismo se entiende como un sector de la economía que utiliza las potencialidades de un determinado espacio geográfico para, a través de la organización de una oferta tangible, ofrecer oportunidades a un público objetivo para la satisfacción de unas expectativas específicas. Así las potencialidades tanto tangibles (atractivos naturales o creados) como intangibles (clima, cultura, eventos) se conjugan con una serie de servicios adecuados (restaurantes, alojamiento, transporte, animación) y con una infraestructura de soporte (servicios públicos, vías de transporte, comunicaciones) para configurar la denominada "Oferta Turística" (Beltrán Vargas, López Bandera \& Gómez Tobón, 2002).

Estas potencialidades tangibles o intangibles son las que se denominan "Atractivos" y se configuran en determinantes de la existencia de una oferta turística, toda vez que de estos dependen las características de los servicios y las particularidades de la infraestructura de soporte. En Colombia, por directriz del Ministerio de Industria, Comercio y Turismo (2010), los atractivos se clasifican básicamente en Sitios Naturales y Patrimonio Cultural. Este último incluye el patrimonio material, el patrimonio inmaterial, las festividades y eventos y los Grupos de Especial Interés, constituidos por comunidades indígenas, negras y raizales.

Así pues, la oferta turística (atractivos, servicios e infraestructura) se convierte en producto cuando se integra en una unidad homogénea para su venta. Conforme dicha oferta genere uno o varios productos turísticos se configuran destinos o regiones (zonas) turísticas (Muñoz de Escalona, 2004) respectivamente. Allí se gestan modificaciones y alteraciones al territorio donde la oferta se asienta y se permean las posibilidades para declararlo turístico, conforme dichos atractivos ocupan una parte importante del espacio geográfico y su potencialidad se convierte en el eje de las actividades sociales, económicas, políticas y ambientales del territorio ocupado.

Como renglón de la economía mundial, y motor de movimiento de miles de personas alrededor del mundo, el turismo se forja a partir de lineamientos internacionales que engranan la actividad económica con su ingrediente humano y de desarrollo sostenible, en la configuración de códigos de aceptación mundial, base para la legislación y la configuración de políticas en los niveles supranacionales, nacionales y subnacionales. Los lineamientos internacionales hacen especial énfasis en la sostenibilidad como meta importante del desarrollo económico emanado del turismo. 
En este sentido, es esencial que la oferta turística aproveche en primera instancia las potencialidades que ofrece el territorio, para que a partir de las regiones puedan ser generados destinos y productos económicamente viables, socialmente beneficiosos y ambientalmente amigables tanto para propios como para visitantes.

La Organización de Naciones Unidas, a través de la Organización Mundial del Turismo (OMT), se ocupa del desarrollo de un turismo responsable, sostenible y accesible para todos. Los programas de la OMT promueven el cumplimiento del Código Ético Mundial para el Turismo, en pos de los Objetivos de Desarrollo del Milenio, con el ánimo de evitar que el turismo tenga impactos negativos sobre el medio ambiente y el patrimonio cultural, esto con el fin de propender por beneficios para los residentes de los territorios identificados como turísticos (Organización Mundial del Turismo, 2001). Dicho documento involucra a los diferentes actores que hacen parte de la organización del turismo en los territorios, fijando pautas de acción que permitan una gestión coordinada y coherente.

El Consejo Global de Turismo Sostenible (por sus siglas en inglés GSTC), constituido en 2010 como una alianza entre organizaciones y Estados, iniciativa patrocinada por la OMT, configura en 2013 los "Criterios Globales de Turismo Sostenible", como el principio de un proceso para convertir la sostenibilidad en práctica estándar en todas las formas de turismo. Se pretende con ellos guiar a las organizaciones para la "gestión turística efectiva en los destinos turísticos", a partir de cuatro ejes principales:

a. Demostrar una gestión sostenible eficaz.

b. Maximizar los beneficios sociales y económicos para la comunidad local y minimizar los impactos negativos.

c. Maximizar los beneficios para el patrimonio cultural y minimizar los impactos negativos.

d. Maximizar los beneficios para el medio ambiente y minimizar los impactos negativos (Consejo Global de Turismo Sostenible, 2013).
Las políticas y planes globales han destacado la búsqueda de la competitividad como estrategia de mercado, que redunda en los factores de sostenibilidad ya mencionados: "La competitividad se trata de generar en el espacio, un entorno físico, tecnológico, social, ambiental e institucional propicio para atraer y desarrollar actividades económicas generadoras de riqueza y empleo" (Cabrero, Orihuela \& Zicardi, 2003).

A partir de los lineamientos de la Política Nacional de Competitividad aprobados por la Comisión Nacional de Competitividad en el año 2007, se establece la Visión Estratégica de Competitividad y Productividad para Colombia:

En 2032 Colombia será uno de los tres países más competitivos de América Latina y tendrá un elevado nivel de ingreso por persona equivalente al de un país de ingresos medios altos, a través de una economía exportadora de bienes y servicios de alto valor agregado e innovación, con un ambiente de negocios que incentive la inversión local y extranjera, propicie la convergencia regional, mejore las oportunidades de empleo formal, eleve la calidad de vida y reduzca sustancialmente los niveles de pobreza" (Politica Nacional de Competitividad y Productividad, 2008).

Dentro de los planes de acción para lograr dicha visión, el Consejo Nacional de Política Económica y Social (CONPES) define al turismo como uno de los sectores o clusters de clase mundial, cuyo desarrollo se debe tener en cuenta con relación a su impacto sobre la competitividad del país. Así, define la competitividad como "el complemento a las condiciones de entorno para el crecimiento del país". En este sentido, asume que las condiciones del entorno están dadas y que a través de la búsqueda de competitividad, medida con base en la productividad, se logrará el cumplimiento de la Visión establecida en un horizonte de 25 años. Teniendo en cuenta que la productividad es responsabilidad sobre todo del sector privado, el Estado deberá conceder estas condiciones de entorno en donde la empresa privada pueda ser 
productiva y por ende se logre ser competitivo en un entorno mundial.

Francés indica que para el logro de la competitividad turística en un determinado territorio se deben tener en cuenta cinco factores, a saber:

a. Factor Atractivo: Referido a la valoración que se hace del lugar u objeto específico que motiva el viaje. Para su evaluación se han establecido metodologías de planificación del turismo desde el Ministerio de Comercio, Industria y Turismo -MINCIT, las cuales permiten valorar los atractivos de acuerdo a su naturaleza, su calidad y su significado.

b. Factor Disuasivo: Representa la imagen que se maneja del lugar en ámbitos de origen del turista, y que se traduce en la imagen creada del destino. Se incluyen las ventajas comparativas, los diferenciadores y las noticias de acontecimientos en el lugar que generan riesgo de viaje.

c. Factor oferta: $\mathrm{O}$ capacidad de carga del lugar para soportar el arribo de los turistas en determinadas temporadas, sumando a ello las actividades programadas y la existencia de locales adecuados para su realización, así como para la prestación de servicios indispensables. Tiene una relación directa con la sostenibilidad, en la medida que la explotación turística no resulte perjudicial para los ciudadanos, para el medio ambiente o para la gestión económica y política.

d. Factor Experiencia: Depende de la satisfacción real que el lugar generó en el visitante, la repetición en las visitas y la multiplicación de la experiencia positiva en los lugares de demanda.

f. Factor Costo: Medible desde los precios del paquete, enfrentado a los precios de destinos similares (Francés, 2003).

Aunque existen muchas determinantes que se asocian para el logro de la competitividad en una región o país, para el tema turístico -compaginando los factores de competitividad propuestos por Francés con la Visión Nacional 2032 y las líneas de acción establecidas para su cumplimiento-, se construyen perspectivas de análisis conforme a la metodología propuesta por Kaplan y Norton (2002), que permitan identificar los actores claves para la organización de destinos competitivos y sostenibles:

a. Perspectiva del cliente: Delimitada por el disfrute de la experiencia turística y las expectativas del turista al elegir un destino o región turística específica.

b. Perspectiva del proceso: Representada en la búsqueda de la productividad para la prestación de servicios turísticos (gestión privada).

c. Perspectiva de las capacidades: Indicada por la intervención de las entidades u organizaciones promotoras o planificadoras en el territorio (gestión pública).

d. Perspectiva de la comunidad: como receptora de los beneficios económicos del turismo en lo local y garante de la oferta (Torres López, 2011).

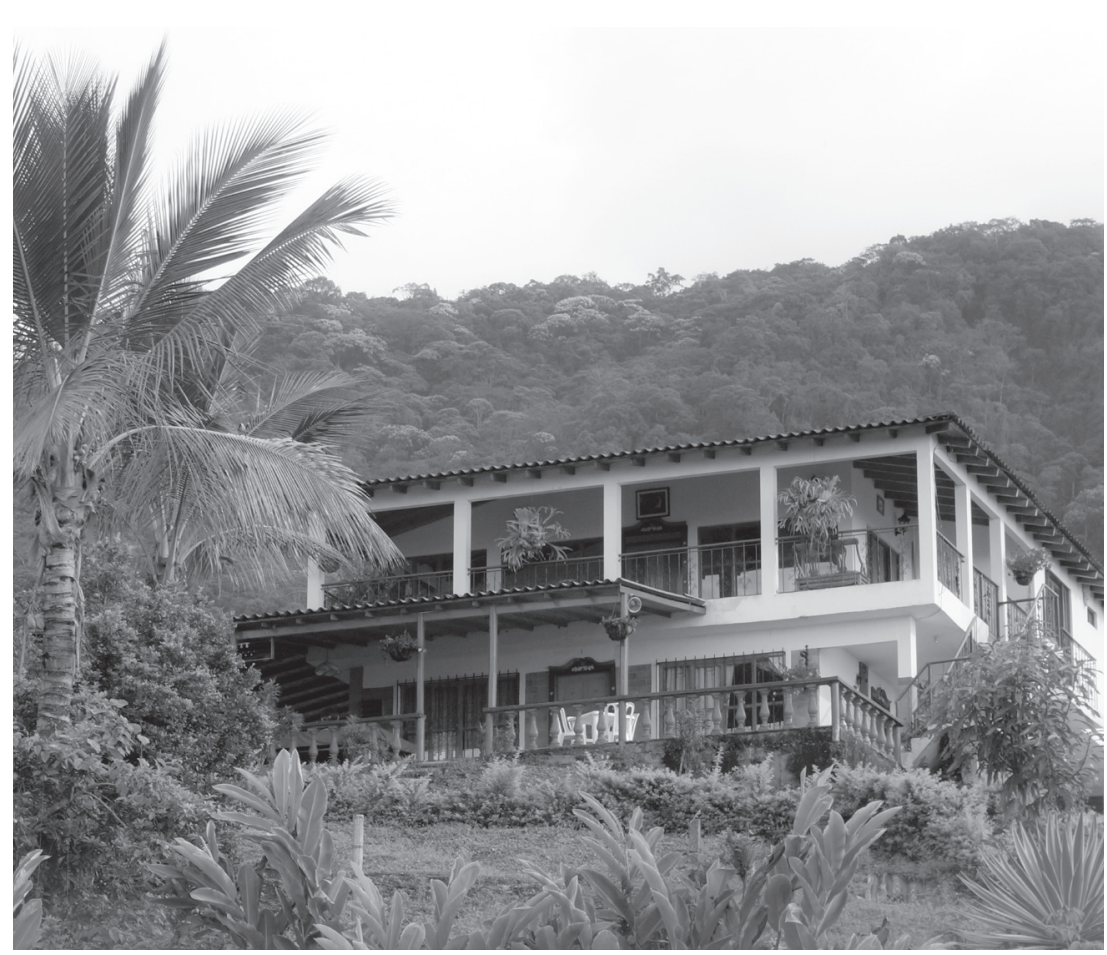

Revista nodo • ISSN 1909-3888 • Vol. 10(20) • Julio-Diciembre 2016 
La gestión competitiva del turismo en un determinado espacio geográfico depende entonces de la articulación y coordinación de acciones entre el sector público, el sector privado y la comunidad que habita y conforma este territorio, con el fin de cumplir con las expectativas del turista en aras de la sostenibilidad del destino o región turística. Las perspectivas expuestas cobran vital importancia al definir el territorio, no sólo a partir de las jurisdicciones como "la descripción formal de los límites legales" (Rinaudo, 2004), sino a través de la visión sistémica que trasciende el espacio físico y los límites geográficos o políticos, fortaleciendo el papel del ser humano como transformador a partir de su apropiación y uso (Mosquera, 2013), por lo que se pasa de un espacio estático a un espacio dinámico que comparte características como la identidad cultural o los ecosistemas, lo que implica cambios en su configuración geográfica a partir de las manifestaciones, procesos o articulaciones de los sistemas sociales que lo habitan (Santos, 2000).

\section{Ordenamiento territorial para el turismo en Colombia}

En Colombia, Estado social de Derecho, la Constitución Política de 1991 ordena los asuntos legislativos y normativos en el país. Olano García (2008), con base en el modelo Kelseniano, formula la pirámide normativa en el ámbito nacional con el siguiente orden básico: Constitución Política, Leyes Aprobatorias de Tratados Internacionales, Leyes estatutarias, Leyes orgánicas, Leyes Marco, Leyes Ordinarias y Decretos-Ley.

En asuntos turísticos, este ordenamiento jurídico se concreta conforme se demuestra en el siguiente cuadro:

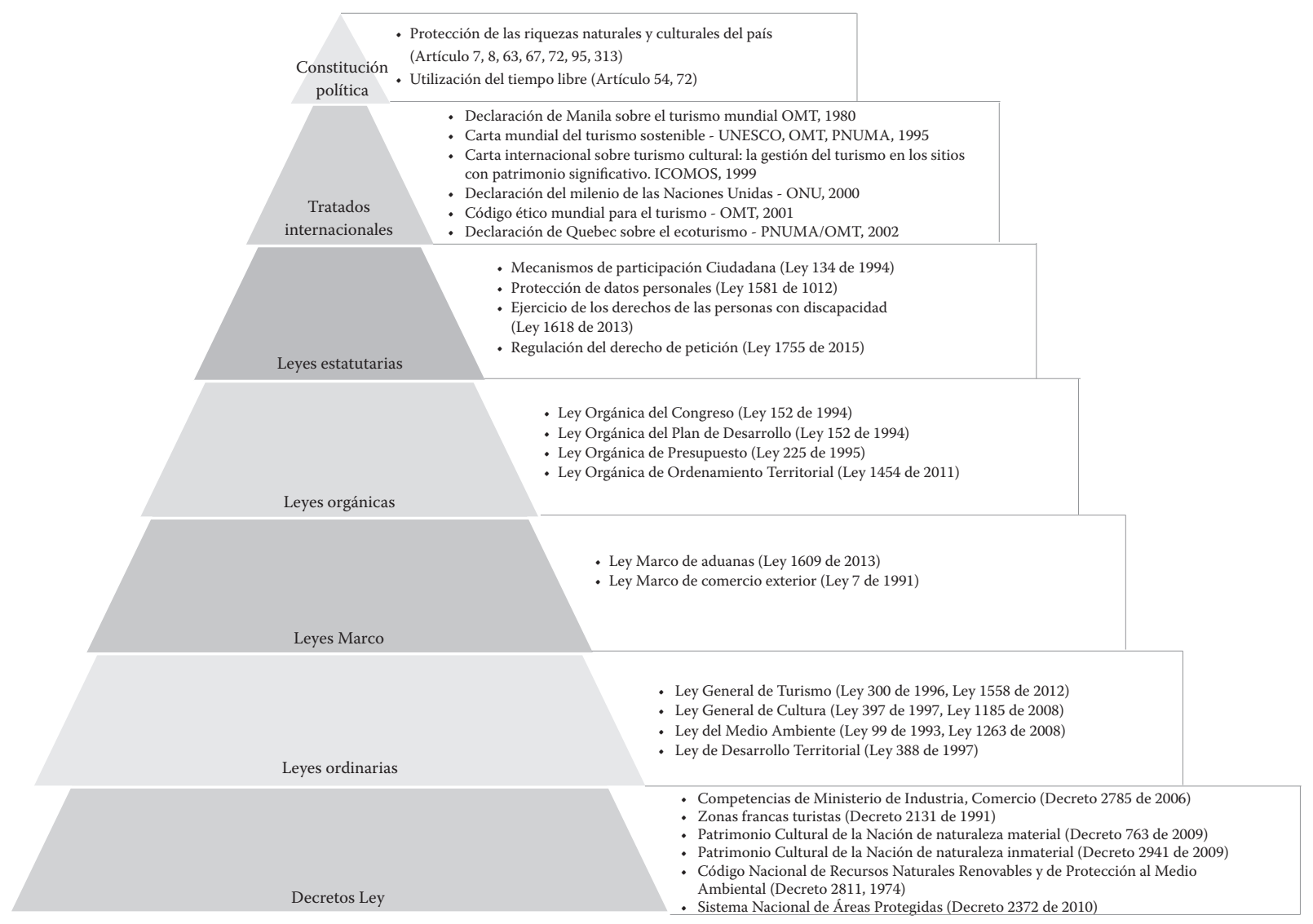

Elaboración propia, complementando a Torres (2010). 
Como elemento primordial, la Constitución Política, en su artículo 1 establece:

Colombia es un Estado Social de Derecho, organizado en forma de República unitaria, descentralizada, con autonomía de sus entidades territoriales, democrática, participativa y pluralista, fundada en el respeto de la dignidad humana, en el trabajo y la solidaridad de las personas que la integran y en la prevalencia del interés general" (C. Pol., 1991, Artículo 1).

Las entidades territoriales definidas por la misma Carta Magna, gozan de autonomía para la gestión de sus intereses, con los derechos de gobernarse por autoridades propias, ejercer las competencias que les correspondan, administrar los recursos y establecer los tributos necesarios para el cumplimiento de sus funciones, y participar en las rentas nacionales (C. Pol., 1991, Artículo 287).

Las competencias territoriales, entendidas como la base principal de la descentralización administrativa en el país, implican la facultad o poder jurídico que se otorga a las entidades territoriales y a las figuras de integración regional para ejercer responsabilidades estatales (Ley 1454, 2011), garantizando la autonomía de los entes territoriales para la planeación, gestión y administración de sus propios intereses, con el apoyo necesario de los recursos de la Nación. (Procuraduría General de la Nación, 2011). Conforme a la Carta Política: "Las competencias atribuidas a los distintos niveles territoriales serán ejercidas conforme a los principios de coordinación, concurrencia y subsidiariedad en los términos que establezca la Ley" (C. Pol., 1991, Artículo 288).

Por orden constitucional, la Ley Orgánica de Ordenamiento Territorial -LOOT (Ley 1454, 2011), aporta los principios rectores para la asignación de competencias a las entidades territoriales para cada materia específica, lo cual implica en el tema turístico la conciencia en la entidad territorial de la posibilidad abierta para conformar esquemas asociativos que le permitan actuar como destino, conforme a sus propios intereses. En este marco se adhieren además las Corporaciones Autónomas Regionales (Artículo 9), quienes configuran una estructura geográfica diferente a la establecida por las entidades territoriales.

Los esquemas asociativos territoriales (Tít. II, Cap. II) que podrán establecerse sin necesidad de una continuidad geográfica, en todos los casos son competentes para organizar conjuntamente la prestación de servicios o la ejecución de obras públicas de interés común, cumplir funciones de planificación y procurar el desarrollo integral de los territorios. En este sentido son las instancias llamadas para desarrollar las metodologías de planificación turística regional propuestas por el MINCIT. Fuera de estos esquemas asociativos están las regiones administrativas y de planificación, conformadas por dos o más departamentos, o departamentos y distritos, que tengan continuidad geográfica, cuya competencia será promover el desarrollo económico de sus territorios y el mejoramiento social de sus habitantes.

Debido a la demora en la promulgación de la LOOT, el Gobierno Nacional desarrolló leyes ordinarias conducentes a la ejecución del ordenamiento en las entidades territoriales, caso de la Ley 388 de 1997, junto a políticas y normativas diversas que inducen a los territorios en el cumplimiento de determinadas actividades o funciones propias de su nivel de gobierno, en cada uno de los sectores de la economía. Para el sector turismo, la existencia de las subsiguientes leyes ordinarias conforme a la pirámide normativa expuesta, se desarrollan en tres ámbitos fundamentales: el ambiental, el cultural y el netamente turístico.

La Ley de Medio Ambiente (Ley 99, 1993) y el Código Nacional de Recursos Naturales Renovables y de Protección al Medio Ambiente -CNRNR (Decreto 2811, 1974), reglamentado por el Decreto 2372 de 2010, concretan el Sistema Nacional de Áreas Protegidas SINAP, compuesto por Áreas Protegidas Públicas (Sistema de Parques Nacionales Naturales, Reservas Forestales Protectoras, Parques Naturales Regionales, Distritos de Manejo Integrado, Distritos de Conservación de Suelos y Áreas de Recreación) y Áreas Protegidas Privadas 
(Reservas Naturales de la Sociedad Civil). El SINAP se constituye en el conjunto de instrumentos de ordenamiento del territorio desde el componente ambiental.

Desde lo cultural, la Ley General de Cultura (Ley 397, 1997), modificada y adicionada por la Ley 1185 (2008), establece los instrumentos para la gestión territorial del Patrimonio Cultural. Entre éstos se destacan los planes Especiales de Manejo y Protección PEMP (Artículo 11); los Planes de Manejo Arqueológico (Artículo 11); y los Planes de Salvaguardia (Artículo 11).

Por último, en este nivel normativo es importante señalar la Ley General de Turismo (Ley 300, 1996), reglamentada por el Decreto 2785 de 2006 y modificada por las leyes 1101 de 2006 y 1558 de 2012, la cual, sin ser expresamente de su resorte, fija las competencias que en materia turística le corresponden a las entidades territoriales. De allí se desprende la formulación por parte de la Nación del Plan Sectorial de Turismo 2014-2018: Turismo para construir la $\mathrm{Paz}$ (Ministerio de Industria, Comercio y Turismo; Departamento Nacional de Planeación, 2014). La Ley General es bastante explicita en las competencias de planeación del turismo en los departamentos y municipios, sin considerar las acciones frente al establecimiento de los esquemas asociativos de que trata la LOOT. Dispone además de algunos instrumentos para la gestión del desarrollo local del turismo, como los programas de asistencia técnica -metodologías de planificación turística regional- (Artículo 13) ${ }^{2}$; las zonas de desarrollo turístico prioritario (Artículo 18); las zonas francas turísticas (Artículo

2 "El Viceministerio de Turismo perteneciente al MINCIT, como órgano encargado de la generación de las políticas nacionales, así como de la planificación del turismo, con base en los principios de descentralización y coordinación, y en virtud del apoyo y asesoría técnica que debe brindar como parte de sus funciones, configura seis metodologías de planificación del turismo, que permita a las regiones realizar la planificación adecuada conforme a sus vocaciones, sus determinantes y sus propósitos específicos" (Asistencia técnica en planificación del turismo, 2008).
9, Decreto 2131 de 1991); el recurso turístico de utilidad pública (Artículo 23, 24); los peajes turísticos (Artículo 25); así como los círculos metropolitanos-Turísticos (Artículo 109). ${ }^{3}$

Este ordenamiento jurídico para lo territorial y los esquemas asociativos expuestos en la LOOT implican dirigir el desarrollo de los territorios a partir de las denominadas regiones pivotales y regiones virtuales, según las denominara Boisier (1995), entendidas las primeras como aquellos territorios identificables claramente -el caso de las divisiones político-administrativas existentesy las segundas como el resultado de acuerdos entre dos o más regiones pivotales para alcanzar objetivos definidos. La teoría de Boisier pone de manifiesto que no es suficiente, dadas además las condiciones ya descritas del territorio nacional, contar con una gestión del territorio enfocada únicamente desde la perspectiva de los niveles de gobierno y sus organizaciones (perspectiva de las capacidades), sino que es necesario enfocarse en la interjurisdiccionalidad (capacidades interconectadas y complementarias) y en su integralidad con las perspectivas del cliente, de los procesos y de la comunidad, en la búsqueda de objetivos de desarrollo territorial específicos y adecuados a unas condiciones territoriales homogéneas.

Todo lo anterior confirma la visión sistémica del desarrollo territorial, lo que implica que este desarrollo es el resultado del potencial productivo del lugar, en primera instancia, y no es posible concebirlo sin planificar la inversión para el mejoramiento u optimización de los recursos sobre los cuales se fundamenta y por tanto de su correcta gestión (López Palomeque, 1997), bajo criterios de sostenibilidad política, económica, cultural,

\footnotetext{
3 "Los municipios podrán conformar Círculos Turísticos con el fin de promover y desarrollar el turismo en sus regiones, de acuerdo a lo establecido en la Ley 1454 de 2011, LOOT. Estos Círculos podrán formular proyectos al Banco de Proyectos del Fondo Nacional del Turismo" (Artículo 28, Ley 1558 de 2012). Estos círculos turísticos se convertirían en entidades territoriales conforme a lo expuesto en la LOOT.
} 


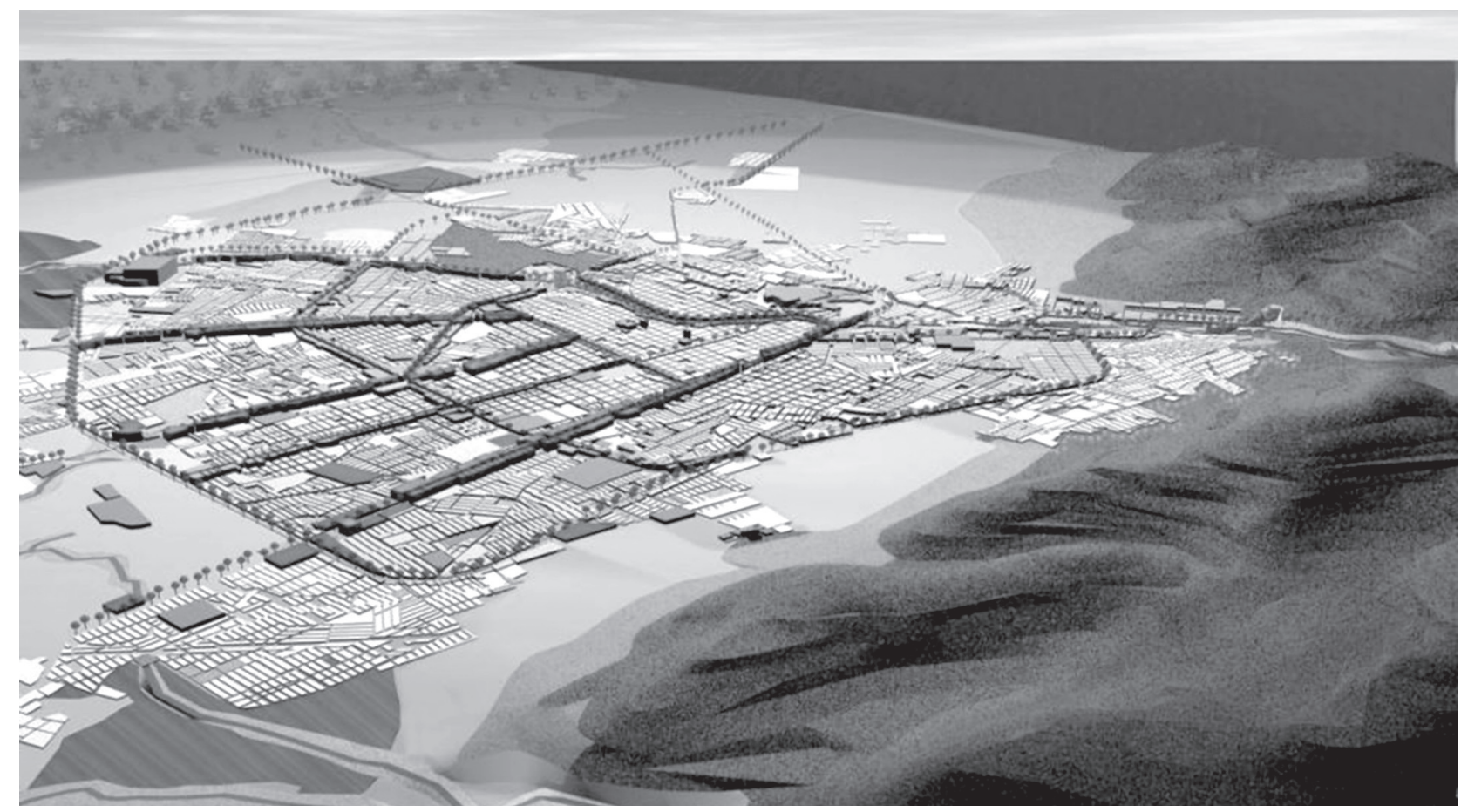

ambiental, tecnológica y social, con el fin de adaptarse a los lineamientos internacionales pertinentes.

Las políticas de Estado derivadas de este ordenamiento jurídico, buscan propiciar la planeación y la gestión para configurar un territorio sistémico que permita a los habitantes ser partícipes del desarrollo a partir de engranajes de actuación público-privada, que involucren todas las perspectivas manifiestas en una visión holística territorial. Se destaca en primer término la propuesta promulgada con motivo del Bicentenario de la República, que desarrolla la prospectiva frente a lo que se espera del país en año 2019, cuya visión en materia de descentralización y ordenamiento territorial establece:

Para 2019, el país habrá consolidado una política de descentralización y ordenamiento que promueva la autonomía territorial, clarifique la distribución de competencias, asigne recursos de una manera equitativa y eficiente, y reconozca la heterogeneidad regional. Dicha política se enmarcará dentro de un ordenamiento territorial flexible que permita trascender los límites político administrativos y posibilite una organización espacial acorde con las dinámicas regionales" (Departamento Nacional de Planeación, 2005).

La necesidad de la Ley Orgánica de Ordenamiento Territorial se hace evidente en la Visión, con el fin de cerrar las brechas en cuanto a reconocimiento de la diversidad nacional, reflejada no en índices de desarrollo humano, asunto en el que debería ser homogénea, sino en riquezas culturales y naturales. Sin embargo, la LOOT promulgada en 2011 se concentra en proponer esquemas de asociación y posibilidades de engranaje territoriales entre las Entidades promulgadas por la Constitución y existentes, en cumplimiento de la meta de trascender los límites jurisdiccionales sin ahondar en las competencias específicas de cada una de ellas y considerando su configuración como territorio, tal como se definió anteriormente, posible a través del reconocimiento de los sistemas sociales que lo conforman. 
La Visión II Centenario: 2019, considerando que se trata de una Visión sectorizada que no posee definición de un modelo de ordenamiento territorial donde se espacialicen las apuestas de desarrollo nacional y su relación con el territorio (Departamento Nacional de Planeación, 2014) se renueva y concreta como Política de Estado en el documento CONPES 3527, Política Nacional de Competitividad y Productividad (2008), con un horizonte de mayor alcance, el de 2032. Este ejercicio prospectivo, también anterior a la promulgación de la LOOT, indica como uno de sus objetivos la promoción de sectores de clase mundial, destacando dentro de ellos al turismo. Dentro de sus estrategias, entre otras propone la elaboración de un plan de acción que defina responsabilidades y competencias de las entidades territoriales en materia turística, y la reglamentación para el cumplimiento de los compromisos establecidos en los convenios de competitividad del sector, instrumentos de gestión que fijan de manera específica las competencias en los niveles público, privado, regional y local, visualizándose como la herramienta de la descentralización administrativa para el turismo.

A partir de las discusiones del DNP y del Comité Especial Interinstitucional de la Comisión de Ordenamiento Territorial organizado a partir de la expedición de la LOOT, considerando la prospección de nuevas realidades para el país en congruencia con los lineamientos emanados de los Objetivos del Milenio y el escenario del posconflicto, precisa atender cinco asuntos principales:

a. Ajustar a las condiciones del entorno natural las dinámicas económicas y sociales que inciden en el uso y la ocupación del territorio.

b. Dirigir el Ordenamiento Territorial de manera proactiva y preventiva frente a la vulnerabilidad del territorio al cambio climático y otras amenazas de origen antrópico.

c. Orientar las decisiones de localización de asuntos de interés nacional relacionadas con la sostenibilidad, la competitividad, la equidad territorial y la gobernanza del territorio, anticipando conflictos y aprovechando las oportunidades de desarrollo, tanto en lo sectorial como en lo regional.

d. Implementar normas, instrumentos y competencias para el ordenamiento territorial articulados en los diferentes niveles de gobierno para que su aplicación atienda a una visión integral y estratégica del territorio.

e. Coordinar el sistema de planeación territorial con los instrumentos de ordenamiento territorial; que permita que las entidades con competencia en el ordenamiento y el desarrollo territorial interactúen de manera coordinada y continua (Bases para la formulación de la Política General de Ordenamiento Territorial, 2014).

En este sentido, El Plan Sectorial de Turismo 20142018, como política pública para este sector de la economía, acogiendo las directrices de gestión sostenible promulgadas por la Organización Mundial del Turismo -OMT y la Constitución Política, indica como objetivo general:

Posicionar a Colombia como destino turístico sostenible y sustentable, reconocido en los mercados mundiales y valorado en los mercados nacionales, por su multiculturalidad y megadiversidad, con una oferta altamente competitiva, que lleve a su máximo nivel a la industria de los viajes y al turismo como potenciador del desarrollo regional y constructor de paz" (Ministerio de Industria, Comercio y Turismo; Departamento Nacional de Planeación, 2014).

Dicho plan basa su desarrollo en la cultura de la competitividad, elemento clave en la construcción sectorial, sin embargo no se articula a la política de productividad y competitividad con Visión 2032, lo que demuestra la falta de concurrencia entre los actores del Estado, que se refleja en las acciones emprendidas una y otra vez por las enti- 
dades territoriales. Es claro que estas políticas dispersas y faltas de continuidad disminuyen la gestión en los territorios, agotando a los actores involucrados en los procesos.

\section{Conclusiones}

El turismo, como actividad económica y como actividad humana, influye en la organización y ordenamiento del territorio, por cuanto los espacios territoriales requieren amoldarse al movimiento turístico según la naturaleza de la oferta. Los modelos utilizados mundialmente pueden ser aplicables en entornos similares, más aún cuando los lineamientos internacionales ven al turismo como una estrategia generadora de desarrollo sostenible para las regiones. Por tanto, las organizaciones trasnacionales promueven el desarrollo sostenible mediante procesos que involucren, en su concepción, la participación activa de las comunidades receptoras con criterios de respeto y responsabilidad. Esto significa que para la adecuada gestión del turismo como promotor del desarrollo sostenible en las regiones, es necesario sustentar sus procesos en los lineamientos referidos al turismo como sector de la economía y siempre en constante relación con los preceptos del ordenamiento territorial.

El turismo comparte las preocupaciones de gestión territorial y urbana con los sectores ambiental y cultural, convirtiéndose en complementario de éstas a partir de su configuración como posibilidad de explotación económica del patrimonio. En Colombia, la expedición de la Ley Orgánica de Ordenamiento Territorial LOOT, genera elementos de valor para la asociación de entidades territoriales e instancias de integración regional, permitiendo mediante estas últimas configurar territorios desde lo turístico que permitan la aplicación de las herramientas que la legislación ofrece desde lo ambiental, lo cultural y lo turístico, así como la generación de metodologías técnicas adecuadas para su planificación, permitiendo la movilidad regional y la integración de regiones, destinos y productos consolidando a través de ello una imagen integral que promueva la realidad de la oferta. Es imperativo resaltar que la planeación y el ordenamiento deberán partir de la vocación de los territorios frente a sus potencialidades, y que siempre que éstas sean dirigidas a la identificación de atractivos conformados por uno o varios productos, se pueden definir y configurar destinos o regiones de vocación turística que permitan engranar las acciones desde lo privado y las competencias desde lo público para concretar los esquemas asociativos territoriales que propone la LOOT, con el fin de elevar la competitividad territorial hacia esa visión del turismo de clase mundial.

Del cruce de la información emanada del ordenamiento normativo y teniendo en cuenta la prevalencia de la ley conforme a su naturaleza, se concluye, a modo de propuesta de gestión, que las competencias aplicables a cada entidad territorial e instancias de integración regional, conformadas como esquemas asociativos territoriales en la LOOT, y dirigidas a la planificación, gestión y promoción del turismo se organicen así:

- La Nación identifica los atractivos y genera las políticas. En este sentido define el destino y configura el territorio a partir de una visión sistémica holística para dirigirlo hacia la competitividad en la unidad de Nación.

- Las regiones Administrativas y de Planificación promueven el desarrollo sostenible de sus territorios y el mejoramiento social de sus habitantes.

- Las instancias de integración regional y las áreas metropolitanas, organizan conjuntamente la prestación de servicios o la ejecución de obras públicas de interés común, y planifican el desarrollo integral de los territorios.

- Los departamentos y los distritos orientan la proyección espacial de los planes sectoriales en el área de su jurisdicción, estableciendo directrices para la conformación de regiones, destinos o productos turísticos. 
- Las CAR asesoran cuando sea necesario en el tema ambiental.

- Los municipios y los distritos ejecutan de acuerdo a lo establecido en los niveles superiores.

Convertirse en destino turístico sostenible y competitivo de clase mundial, como lo advierten los ejercicios prospectivos, requiere el concurso de diversos actores públicos y privados en los niveles nacional, regional y local, y la coordinación de los distintos niveles del Estado en concurrencia y subsidiariedad constante. Al final, aunque la Ley General de Turismo (Artículo 17) incite a la generación de planes sectoriales en todas y cada una de las entidades territoriales, elemento generalmente presente en los convenios de competitividad suscritos entre la Nación y las entidades territoriales, lo que interesa será la orden constitucional de coordinación, concurrencia y subsidiariedad, que tanta falta hace en los procesos planificadores del turismo en la actualidad (Muñoz de Escalona, 2004).

\section{Referencias bibliográficas}

Ardila, G. (2006). Cultura y Desarrollo Territorial. Diplomado de Procesos Culturales y Construcción de lo Público. Bogotá: Instituto Distrital de Cultura y Turismo.

Beltrán Vargas, H., López Bandera, H., \& Gómez Tobón, J. (2002). Gestión y Desarrollo del Turismo Regional. Bogotá: Universidad Externado de Colombia.

Cabrero, E., Orihuela, I., \& Zicardi, A. (2003). Ciudades competitivas-ciudades cooperativas: conceptos claves y construcción de un índice para ciudades mexícanas. México: CIDE.

Consejo Global de Turismo Sostenible (1 de noviembre de 2013). "Criterios Globales de Turismo Sostenible para Destinos Turísticos". Recuperado de: [http://www.gstcouncil.org/en/ docs/file/401-spanish-criteria-for-destinations. html].
Constitución Política de Colombia (1991). Bogotá, Colombia: Imprenta nacional.

Decreto 2785, Estructura del Ministerio de Comercio, Industria y Turismo (Ministerio de Industria, Comercio y Turismo, 17 de agosto de 2006).

Decreto 2811, Código Nacional de Recursos Naturales Renovables y de Protección al Medio Ambiente (Congreso de la República 18 de diciembre de 1974).

Departamento Nacional de Planeación (2005). Visión Colombia II Centenario 2019. Bogotá: Planeta.

Departamento Nacional de Planeación (octubre de 2014). "Bases para la formulación de la Política General de Odenamiento Territorial". Recuperado de: [https://colaboracion.dnp.gov.co/CDT/ Desarrollo\%20Territorial/Bases\%20PGOT_ Octubre\%202014.pdf].

Francés, A. (2003). Turismo: competitividad y estrategia. Planes de desarrollo de destinos turísticos con el cuadro de mando integral. Caracas: IESA.

Kaplan, R., \& Norton, D. (2002). Cuadro de Mando Integral. Barcelona: Gestión 2000.

Ley 1185, Ley General de Cultura (Congreso de la República, 12 de marzo de 2008).

Ley 1454, Ley Orgánica de Ordenamiento Territorial (Congreso de la República, 28 de junio de 2011).

Ley 1558, modifica la Ley 300 de 1996, Ley General de Turismo (Congreso de la República, 10 de julio de 2012).

Ley 300, Ley General de Turismo (Congreso de la República, 26 de julio de 1996).

Ley 397, Ley General de Cultura (Congreso de la República, 7 de agosto de 1997).

Ley 99, Ley de Medio Ambiente (Congreso de la República, 22 de diciembre de 1993). 
López Palomeque, F. (1997). Análisis territorial del Turismo: Una nueva geografía del turismo. Barcelona: Ariel.

Ministerio de Industria, Comercio y Turismo. Viceministerio de Turismo (2010). Asistencia técnica en planificación del turismo. Bogotá.

Ministerio de Industria, Comercio y Turismo (2010). Metodología para la elaboración del inventario de atractivos turísticos. Bogotá.

Ministerio de Industria, Comercio y Turismo; Departamento Nacional de Planeación (2014). Plan sectorial de turismo 2014-2018: "Turismo para la construcción de la paz". Bogotá.

Mosquera, J. (29 de noviembre de 2013). “Diplomado en desarrollo regional y participación para la gobernabilidad en frontera desde la prospectiva territorial". Universidad de Pamplona. Recuperado de: [http://www.unipamplona.edu. co/unipamplona/portalIG/home_52/recursos /01general/29112013/sesion3_modulo3.pdf].

Muñoz de Escalona, F. (2004). Los conceptos del turismo: invitación al debate en diez preguntas. Contribuciones a la Economía.

Olano García, H. (2008). "La ley como sinónimo de ordenamiento jurídico”. Revista de Derecho (30), pp. 75-113.
Organización Mundial del Turismo (2001). Código Ético Mundial para el Turismo. Madrid: Naciones Unidas.

Política Nacional de Competitividad y Productividad, 3527 (Consejo Nacional de Política Económica y Social, CONPES, 27 de junio de 2008).

Porter, M. (2009). Ser competitivo. Barcelona: Deusto.

Procuraduría General de la Nación (2011). Descentralización y entidades territoriales. Bogotá: Instituto de Estudios del Ministerio Público.

Rinaudo, U. (2004). Gestión del desarrollo territorial: aspectos teóricos y metodológicos para la realización de planes de desarrollo regionales $y$ locales. Bogotá: Universidad Piloto de Colombia.

Santos, M. (2000). La naturaleza del espacio. Técnica y tiempo, razón y emoción. Barcelona: Ariel.

Torres López, M. (2010). "Enfoques, normativas e instrumentos aplicables a la gestión regional del turismo en Colombia". Pre-til, pp. 100-109.

Torres López, M. (2011). Gestión del Turismo en Espacios Interjurisdiccionales: Boyacá como Destino Turístico. Bogotá: Universidad Piloto de Colombia. 